\title{
La perspectiva de género y el Derecho del Trabajo: ¿una hermenéutica en construcción o algo más?
}

\author{
Gender mainstreaming and Labour Law: an \\ hermeneutic under construction or something else?
}

\author{
Rafael Moll Noguera* \\ Profesor Ayudante Doctor \\ Departamento de Derecho del Trabajo y de la Seguridad Social de la Universidad de Valencia
}

ORCID ID: 0000-0002-7763-4621

Recibido: $26 / 4 / 2021$

Aceptado: 9/5/2021

doi: https://doi.org/10.20318/labos.2021.6218

Resumen: El estudio de la perspectiva de género como canon hermenéutico por parte del orden social resulta una institución eminentemente casuística, como se verá, pero que surge y se construye en el ámbito de la igualdad entre mujeres y hombres. El estudio parte de una delimitación legal y doctrinal en torno a esta metodología para, de inmediato, trascendiendo a los casos resueltos, identificar las pautas comunes usadas por los jueces, especialmente por el Tribunal Supremo, a la hora de aplicarla. Por último, desde un prisma crítico, se intentará dar respuesta a algunas de las incógnitas que acompañan a esta nueva metodología de aplicación del derecho por los tribunales que giran en torno a los límites a la función integradora, el activismo judicial y el papel del Tribunal Constitucional en todo ello.

Palabras clave: perspectiva de género, igualdad efectiva, función integradora, cuestión de inconstitucionalidad.

Abstract: The Gender mainstreaming's study as a hermeneutical canon by the social order is an eminently casuistic institution, as will be seen, but it arises and is built in the sphere of equality between women and men. The study starts from a legal and doctrinal delimitation around this methodology to, immediately, transcending the resolved cases, identify the common guidelines used by the judges, especially by the Supreme Court, when applying it. Finally, from a critical perspective, an attempt will be made to answer some of the unknowns that accompany this new methodology, which revolve around the limits to the integrative function, judicial activism, and the role of the Constitutional Court. in all this.

Keywords: gender mainstreaming, effective equality, integrating function, question of unconstitutionality. 


\section{Origen y conceptualización teórica de la perspectiva de género}

Como es sabido, esta nueva metodología se institucionaliza y recibe el nombre de "perspectiva de género" a partir de la IV Conferencia Mundial sobre la Mujer celebrada en Beijing en el ańo 1995. Los gobiernos participantes se comprometieron a reflejar la perspectiva de género en todas sus políticas, legislaciones, programas y proyectos públicos. Al igual ocurría en los tratados europeos sobre el tema, véase el Tratado de Ámsterdam (art. 3.2\%) o el de Funcionamiento de la UE (art. 8), en los que su campo de aplicación original se constreñía a la actuación del poder legislativo y ejecutivo, al contemplarse como objetivos de las políticas y acciones legislativas de los Estados.

Es posible detectar un salto cualitativo en el tiempo, aunque tímido, con la aprobación de la Ley Orgánica 1/2004, de 28 de diciembre, de Medidas de Protección Integral contra la Violencia de Género. La razón de ello es que, por vez primera, se positiviza la garantía del principio de transversalidad de igualdad de género, no tan solo en la configuración o desarrollo de políticas públicas, sino también en su aplicación, extendiendo, por tanto, esta nueva metodología al poder judicial. No obstante, este cambio fue tibio por cuanto la norma estaba orientada para tener en cuenta las necesidades y demandas específicas de las mujeres víctima de violencia de género. En cambio, se ensalzó la universalidad objetiva que contemplaba la norma, en la medida que atravesaba todas las ramas del ordenamiento jurídico ${ }^{1}$.

La positivización del principio de perspectiva de género como metodología en la aplicación del derecho aparece definitivamente en nuestro ordenamiento jurídico en el art. 4 de la Ley Orgánica 3/2007, de 22 de marzo, para la Igualdad Efectiva de Mujeres y Hombres. Este precepto eleva la igualdad de trato y de oportunidades entre mujeres y hombres a principio informador del ordenamiento jurídico, ordenando que se integre y observe en la interpretación y aplicación de las normas jurídicas. A mayor abundamiento, el art. 15 de dicho cuerpo normativo consagra la "transversalidad del principio de igualdad de trato entre mujeres y hombres", determinando que alcanza y vincula a todos los Poderes Públicos.

El origen de ambos preceptos es anterior a la refundición de las directivas comunitarias en materia de igualdad que dio lugar a la Directiva 2006/54/CE relativa a la aplicación del principio de igualdad de oportunidades e igualdad de trato entre hombres y mujeres en asuntos de empleo y ocupación de la UE. Con todo, esta directiva positiviza también la perspectiva de género en su art. 29. Así, bajo el nombre "transversalidad de la perspectiva de género", en dicho precepto se hace referencia no solo a la tarea del poder legislativo, sino también al poder judicial para tener en cuenta el objetivo de igualdad entre hombre y mujeres. Asimismo, en el plano internacional es posible identificar alguna manifestación de este concreto principio, especialmente en la Convención sobre la eliminación de todas las formas de discriminación contra la mujer de 1979, ratificada por España en el año 2001. Así, en su art. 2.c) se establece la obligación de que, "por conducto de los tribunales nacionales competentes" se haga efectiva la protección de la mujer contra todo acto de discriminación.

Una vez positivizada, la perspectiva de género en la interpretación y aplicación del derecho laboral se presenta como la plasmación del principio de igualdad de oportunidades con el objetivo de corregir y superar los estereotipos de género encubiertos o latentes en las normas. En puridad, aparece como un mandato directo al conjunto del poder judicial para materializar en sus resoluciones el principio de igualdad efectiva ${ }^{2}$. Por tanto, no se trata de una opción o recomendación para

${ }^{1}$ GIL RUIZ, JUANA MARÍA, La interpretación de las normas bajo una perspectiva de género, 2013. Disponible en ver bibliografía. (20/04/2021)

${ }^{2}$ MOLINA NAVARRETE, CRISTÓBAL, Una cuestión de género en la justicia social: asignatura aún pendiente, también del Tribunal Supremo, Revista de Trabajo y Seguridad Social CEF, núm. 453, 2020, p. 5. 
la buena práctica de la función jurisdiccional, sino que se presenta como una pauta de actuación obligatoria a la hora de interpretar y aplicar las normas.

Así, y a partir de esta definición general es conveniente detenernos en los elementos que la configuran para delimitarla con mayor precisión. En primer lugar, en su fundamento constitucional, a saber, el principio de igualdad; en segundo lugar, en el objetivo concreto que persigue: corregir estereotipos sociales que se replican y aparecen en las normas, muchas veces disfrazados de una aparente neutralidad; y, en tercer lugar, en la metodología en la que se basa: la interpretación y aplicación de normas por el poder judicial.

\subsection{Fundamento constitucional de la perspectiva de género}

El punto de partida de esta metodología es la igualdad efectiva o real, trascendiendo la mera igualdad formal o, lo que es lo mismo, la igualación de mujeres y hombres. En este sentido, se ha denunciado y descubierto que la extensión formal de derechos es claramente insuficiente a los efectos de la igualdad efectiva porque la causa de discriminación es la asignación de roles socioculturales entre mujeres y hombres, el género ${ }^{3}$.

En efecto, la igualdad formal se encamina a hacer desaparecer los síntomas pero no las causas de la desigualdad de género, puesto que el ofrecer las mismas oportunidades a todos por igual no implica que todos puedan disfrutar y ejercitar estos derechos formales de la misma manera ${ }^{4}$. Así pues, la igualdad formal, a diferencia de la real, no atiende a las condiciones materiales que impiden a las mujeres ejercitar sus derechos y obtener un acceso en igualdad a los mismos derechos que los hombres 5 .

Ello no significa, y conviene diferenciar ambos conceptos, que la perspectiva de género como canon hermenéutico se traduzca en un concepto equivalente a la igualdad real, sino que es una manifestación de su realización por parte del poder judicial. Así, siendo el fundamento de este criterio interpretativo la igualdad real, lo novedoso es que la igualdad real no se persiga solamente por el legislador o el ejecutivo mediante fórmulas conocidas de discriminación positiva, sino que el poder judicial se incorpore en su consecución con las herramientas a su alcance, a saber, la interpretación y aplicación de normas.

\subsection{Objetivos que persigue}

En consecuencia con el fundamento de la perspectiva de género, a través de su implantación por parte de los tribunales se procura garantizar la efectividad del principio de igualdad de oportunidades entre mujeres y hombres. Así, el presupuesto aplicativo de este canon hermenéutico es la existencia de una relación asimétrica en la que estén presentes patrones estereotípicos de género. Como acaba de decirse, la búsqueda de la igualdad real y efectiva en la práctica es el objetivo último de esta metodología, superando la mera nivelación o trato idéntico en la norma.

${ }^{3}$ LOUSADA AROCHENA, JOSÉ FERNANDO, La integración de la perspectiva de género en la aplicación e interpretación de las normas por la jurisdicción social, Revista de Derecho Social, núm. 91, 2020, p. 43.

${ }^{4}$ JIMÉNEZ HIDALGO, ADORACIÓN, La precariedad laboral: desigualdad y discriminación, 2018, p. 13. Disponible en ver bibliografía. (21/04/2021).

${ }^{5}$ RODRÍGUEZ-PIÑERO Y BRAVO-FERRER, MIGUEL, Principio de igualdad y Derecho del Trabajo, en XI Jornadas de Estudio El principio de Igualdad en la Constitución española, vol. 2, Madrid, Ministerio de Justicia, 1991, p. 1091. 
Ahora bien, la auténtica virtualidad de esta metodología consiste en procurar corregir déficits de protección o vestigios sexistas que la norma encierra y mimetiza -y que tienen su origen en las brechas de género sociales- mediante una interpretación pro igualdad material de la misma. Así, gracias a ello, la aplicación de la norma no conduciría a mantener la discriminación encerrada en la misma sino que, una vez interpretada con perspectiva de género, se lograría materializar el principio de igualdad real.

En términos negativos, se trata de evitar que el poder judicial realice una lectura y aplicación automática, literal y aséptica de la norma que, al replicar y esconder estereotipos sociales discriminatorios en contra de la mujer, perpetúe y consolide esta discriminación. Por el contrario, gracias a una interpretación de la norma que logre corregir y superar dichos déficits y vestigios sexistas presentes en el ordenamiento jurídico se pretende lograr una solución equitativa en la consecución de la igualdad real entre sexos.

\subsection{Metodología teórica}

Es evidente, desde este enfoque, que los instrumentos disponibles para observar y materializar la perspectiva de género por parte del poder judicial ordinario son la interpretación y aplicación de las normas jurídicas. Así, el órgano judicial, una vez identificada la potencial discriminación que sufre la mujer y que se encuentra escondida en la norma, deberá aplicar la norma en aquella de sus variantes interpretativas que mejor se ajuste al principio de igualdad efectiva de mujeres y hombres.

Como se observa, son dos pues las tareas que la perspectiva de género requiere al órgano judicial para su correcta aplicación: detectar en la norma una discriminación, normalmente oculta o indirecta, que positiviza un estereotipo social contra la mujer; y, en segundo lugar, realizar una interpretación de la norma acorde con el principio de igualdad efectiva para superar dicha discriminación.

Así, y por lo que respecta a la primera de dichas tareas, esta metodología exige mayores dosis de concienciación y análisis crítico a realizar por el poder judicial respecto al funcionamiento de la sociedad, pues solo así se podrá detectar patrones sexistas materializados en la norma. En este sentido, como presupuesto ontológico a la interpretación y aplicación de la norma con perspectiva de género es necesario realizar un análisis global previo de la sociedad para contextualizar la norma aplicable y el conflicto jurídico con el objetivo último de identificar si existen prejuicios de género incorporados a la norma aplicable que se presenta aparentemente neutra. A la hora de acometer esta primera tarea, los tribunales pueden hacer servir diferentes fórmulas que conduzcan a plantear un escenario de discriminación oculta en la norma. Por ejemplo, un posible mecanismo es la utilización de criterios de sustitución o de comparación hipotética para verificar si, en una situación idéntica o similar, un trabajador de sexo masculino habría recibido el mismo tratamiento que una trabajadora. Otra vía es la que se basa en la estadística, y así lo ha entendido el propio TC en la sentencia 91/2019, de 3 de julio, que más adelante se comentará. A tenor de ello, resulta necesario que el poder judicial en los casos de discriminación indirecta atienda necesariamente a los datos revelados por la estadística en el mercado laboral, para analizar el porcentaje de mujeres que se ven perjudicadas por la norma en cuestión y la eventual afectación predominante y mayoritaria del sexo femenino en su aplicación social.

La segunda de las tareas referidas en la que se basa esta metodología engloba dos posibles actuaciones del órgano judicial: por un lado, la interpretación de las normas según los principios generales del derecho y, por otro, el ejercicio de la función integradora.

En este orden, por lo que se refiere a la interpretación de la norma, esta debe realizarse no exclusivamente sobre la óptica tradicional del art. 3 del Código Civil, esto es, la literalidad, el contex- 
to, los antecedentes históricos y legislativos, la realidad social, y el espíritu y finalidad de la norma, sino que se vuelve imprescindible incorporar la perspectiva de género de los art. 4 y 15 de la LO de Igualdad para decantarse por la interpretación, entre las posibles, más cercana y respetuosa con la igualdad efectiva entre hombre y mujeres. Desde este punto de vista, podría afirmarse que los art. 4 y 15 vendrían a corregir y actualizar los criterios tradicionales de interpretación de las normas. En este sentido, conviene recordar que el art. 3.1 del CC no prohíbe el uso de cualquier otro método interpretativo, pues dada su amplitud, la utilización de los valores de las ciencias empíricas extrajurídicas pueden "cobijarse bajo el sentido propio de las palabras o la realidad social del tiempo en que han de ser aplicadas".

Por otro lado, la perspectiva de género como hermenéutica se basa en la función integradora del principio real de igualdad de sexos. Esta segunda vertiente posee una mayor intensidad en cuanto a la actividad del órgano judicial se refiere, pues no se trata ya de optar por la interpretación más acorde al principio de igualdad. Por el contrario, el presupuesto no es simplemente una norma a interpretar, sino que se parte de una laguna normativa que esconde un vestigio sexista de la sociedad, normalmente provocado por la falta de consideración en la regulación positiva del principio de igualdad real. En estos casos, la tarea del órgano judicial consistirá en una labor depuradora de la literalidad de la norma para, por un lado, eliminar el efecto de discriminación sobre las mujeres que resultaría de su aplicación aséptica para, por otro lado, integrar dicha laguna mediante el principio de igualdad efectiva como valor superior de la constitución española.

Conviene despejar que la perspectiva de género no es un principio general del derecho de los que el art. 1.4 del Código Civil contempla ${ }^{7}$, pues precisamente su eficacia no es la de estos, sino que por el contrario, se trata de un principio o valor superior del orden constitucional. Esta distinción resulta importante por cuanto que los principios generales del derecho surgen de la más "pura y dura racionalidad material", es decir, nacen y acompañan al ordenamiento jurídico legal, convirtiéndose en un reflejo del mismo. En otros términos, derivan de las normas jurídicas vigentes en un determinado momento y por ello constituyen el espíritu de la ley ${ }^{9}$. Precisamente por esta razón, la aplicación de los principios generales es subsidiaria y casi residual al presentarse como el último remedio interpretativo de la norma, teniendo valor más interpretativo e integrador que normativo.

Por el contrario, los principios supremos del ordenamiento jurídico plasmados en la Constitución y en los instrumentos supranacionales se presentan como auténticos valores superiores al conjunto del ordenamiento jurídico. Así, la libertad, la justicia, la igualdad y el pluralismo político (art. 1.1 CE) aparecen como las pautas de actuación y de orientación de todos los poderes públicos, al colocarse en una "concepción ética supra-positiva" ${ }^{10}$. Por tanto, la eficacia jurídica de estos principios en nada se parece a la de los principios generales, pues limitan la actuación del legislador y orientan la actuación del poder judicial.

En todo caso, las dos actuaciones descritas relativas a la interpretación y aplicación de normas van más allá del plano legal y se realizan especialmente desde el plano constitucional.

${ }^{6}$ ALONSO GARCÍA, ENRIQUE, La interpretación de la Constitución. Madrid, Centro de Estudios constitucionales, 1984, p. 82.

${ }^{7}$ Manteniendo que sí son equiparables en cuanto a su eficacia GIL RUIZ, JUANA MARÍA, La interpretación de las normas bajo una perspectiva de género, 2013 p. 8.

${ }^{8}$ MERCADER UGUINA, JESÚS R., Los principios de aplicación del Derecho del Trabajo. Formación, decadencia y crisis, Valencia: Tirant lo Blanch, 2014, p. 27.

${ }^{9}$ MONTOYA MELGAR, ALFREDO, La aplicación del Derecho del Trabajo y el sistema de principios, valores y derechos fundamentales, Revista del Ministerio de Trabajo e Inmigración, núm. 88, 2011, p. 27.

${ }^{10}$ Ibidem, p. 17. 
Por último, es importante significar que no resulta fácil aplicar la perspectiva de género tanto por los límites generales derivados del positivismo jurídico ${ }^{11}$ y a los que al final del trabajo se hará referencia, como por la extensión social de los estereotipos sexistas. Este hándicap hace referencia a que los agentes presentes en el ámbito judicial, especialmente los encargados de impartir justicia, al ser ciudadanos de nuestra sociedad fácilmente podrán haber interiorizado y normalizado determinados estereotipos discriminatorios difíciles de identificar en la norma y de corregir. Esta consideración sirve para remarcar la necesaria formación especializada de la judicatura al respecto.

\section{Delimitación y aplicación metodológica de la perspectiva de género por parte del orden social}

\subsection{La aplicación vertical de la perspectiva de género}

La aplicación vertical de la perspectiva de género se refiere a la corrección judicial de una norma que afecta negativamente a la trabajadora en su relación con la acción protectora del Estado. Por el contrario, la aplicación horizontal contemplaría aquellos supuestos en los que la norma es reinterpretada como elemento de ponderación en favor de la igualdad efectiva entre los intereses empresariales y de la trabajadora, generalmente en lo que se refiere a cuestiones de conciliación.

Así, la perspectiva de género vertical encuentra virtualidad práctica en el campo de las normas de seguridad social, en la medida en que están diseñadas, desde su inicio, mediante cánones alejados de la sensibilidad de género y que, por ello, desde una perspectiva de mera igualdad formal, replican y positivizan discriminaciones encubiertas gracias a fórmulas aparentemente neutras.

En detalle, se ha denunciado que la acción protectora del sistema, al estar diseñada en su origen sobre la base de contratos estables y a tiempo completo, coloca al sexo masculino en una posición de superioridad respecto de la mujer, puesto que en este modelo productivo las trabajadoras son las que históricamente han tenido contratos temporales y a tiempo parcial ${ }^{12}$. Estos vestigios normativos machistas se recrudecen si se tiene en cuenta, a su vez, que las normas de seguridad social tampoco tienen en consideración, como regla general, la realidad social y el rol sexista y estereotipado de cuidadora familiar que la mujer sigue desempeńando en ella y que, sin duda, incide en las relaciones de trabajo y, por consecuencia, en la protección que les ofrece el propio sistema de seguridad social. Por estos dos motivos se llega a la conclusión -y presupuesto de partida para la aplicación de la perspectiva de género- de que el sistema, en su conjunto, responde a "patrones y parámetros de valoración pensados exclusivamente para los hombres"13.

Cuantitativamente, hasta el momento, la mayoría de las sentencias que aplican la perspectiva de género como canon hermenéutico lo hacen en el contexto de esta relación vertical. No es casualidad, por tanto, que la primera resolución dictada por el Tribunal Supremo en esta materia fuera en su modalidad vertical. La ya conocida y antigua STS de 21 de diciembre de 2009 (rec. 201/2009), aun con unos mimbres jurídicos en construcción, entendió que la norma encerraba una discriminación oculta provocada por el olvido legislativo al no haber extendido expresamente al régimen -en extinción- SOVI el beneficio de dar por cotizado el tiempo dedicado al cuidado de un recién nacido en los términos fijados para el resto de los regímenes.

${ }^{11}$ POYATOS I MATAS, GLÒRIA, Juzgar con perspectiva de género: una metodología vinculante de justicia equitativa, IQUAL. Revista de Género e Igualdad, núm. 2, 2019, p. 14.

${ }^{12}$ RAMOS QUINTANA, MARGARITA ISABEL, Lesiones en el parto y seguridad social: el enquistamiento de las discriminaciones de sexo y de género, Trabajo y Derecho Nueva Revista de actualidad y relaciones laborales, núm. 71, 2020, p. 2.

${ }^{13}$ Idem. 
En esta sentencia se identifica un punto común, que se repetirá en el resto de las sentencias que aplican la perspectiva de género, consistente en rechazar de entrada la interpretación literal de la norma, al tiempo que pone de manifiesto la necesidad de realizar una interpretación desde el plano constitucional. A continuación, y actuando como segundo anclaje de esta metodología judicial, el tribunal identifica el grupo social discriminado -por razón de sexo-a tenor del déficit de protección de la norma. En concreto, se constata mediante datos e informes que el grupo social que padece este déficit normativo está formado mayoritariamente por mujeres. Debe advertirse, no obstante, que este anclaje de índole sociológico basado en cifras se irá perfeccionado en los vinientes casos, pues en esta ocasión no se detalla ninguna cifra oficial, sino que se toma como un hecho cierto y conocido. Por último, potenciando al máximo la labor interpretativa, y con el objetivo de que la aplicación de la norma no siga provocando la discriminación detectada, el tribunal acude, en esta ocasión, a la finalidad del legislador y a un discutible principio de no exclusión, para entender que el beneficio legislativo para todos los regímenes debe extenderse también al SOVI.

A pesar de constituir, como se ha dicho ya, un mandato al poder judicial, su aplicación no ha resultado constante, ya que tuvo que pasar casi una década para que el Tribunal Supremo -de nuevo, siendo la ponente $\mathrm{M}^{\mathrm{a}}$ Lourdes Arastey Sahún- adoptara la perspectiva de género como canon hermenéutico. Así, sin entrar en detalle por estar la normativa aplicada ya derogada, la STS de 26 de septiembre de 2018 (rec. 1352/2017) realiza una lectura en favor de la igualdad efectiva de los requisitos que acompañaban a la prestación por maternidad compartida con el otro progenitor. No obstante, desde el punto metodológico, es cuestionable su aplicación en la medida en que se limita a afirmar que las normas deben interpretarse a la luz de este principio, pero sin que se opere siguiendo el razonamiento jurídico reflejado en la sentencia del 21 de diciembre de 2009.

La tercera sentencia que nos encontramos aplicando la perspectiva de género en su dimensión vertical es la dictada el 29 de enero de 2020 (rec. 3097/2017), siendo ponente nuevamente $M^{a}$ Lourdes Arastey Sahún. El conflicto jurídico tiene como origen la ausencia de previsión por parte del legislador de que las personas beneficiarias del SOVI tengan acceso a las prestaciones por muerte y supervivencia, pues la norma solo contempla a los titulares de pensiones contributivas de jubilación e incapacidad permanente (arts. 217.1.c y 216.1.g LGSS-2015). Para su resolución, se transita por los tres pasos metodológicos que configuran la aplicación de la perspectiva de género como criterio de hermenéutica normativa. Así, en primer lugar, se rechaza la aplicación literal de la norma, pese a la aparente neutralidad en su redacción, ya que de aplicarla de forma aséptica tendría un impacto más desfavorable para las mujeres, que son las que integran mayoritariamente el colectivo de pensionistas del SOVI. En segundo lugar, se delimita y justifica, mediante el uso de datos y cifras, esta afectación ampliamente femenina, es decir, se demuestra que el grupo discriminado indirectamente por la literalidad de la norma son las mujeres. En tercer y último lugar se acude al criterio finalista y a la analogía para concluir que una pensión SOVI, al tener características análogas y ser contributiva, debe dar acceso a las prestaciones por muerte y supervivencia.

Es durante el año 2020 en el que se puede afirmar que la perspectiva de género se consolida como canon hermenéutico en el Tribunal Supremo. De este modo, unos días después de la anterior, se dicta la sentencia de $\mathbf{6}$ de febrero de 2020 (rec. 3801/2017) en relación con el cómputo, como periodo cotizado, de la prestación del Servicio Social obligatorio de la mujer para acceder a la jubilación anticipada. Se parte de un déficit de protección normativo, al no contemplarse como periodo cotizado dicho tiempo, a diferencia de la previsión expresa respecto del servicio militar obligatorio o prestación social sustitutoria del hombre. De nuevo, la sentencia aplica los tres pasos en los que consiste la perspectiva de género. Así, "no cabe la interpretación del artículo 208.1.b LGSS de forma rígidamente literal" porque conduciría a violar el principio de igualdad. En segundo lugar, se delimita y justifica el grupo discriminado indirectamente por razón de sexo, puesto que "el servicio 
militar lo realizaban únicamente los hombres". Por último, se aplica el criterio de analogía y finalista para superar esta discriminación. De este modo, "se configura como deber tanto la prestación del servicio militar como la prestación del servicio social de la mujer" y "en ninguna de las dos prestaciones hay obligación de cotizar", siendo "la finalidad de ambas prestaciones similar". Como punto final, se hace referencia al art. 4 de la LOIEMH para rematar que las mujeres deben tener el mismo beneficio legal que lo hombres en su acceso a la jubilación anticipada.

El 2 de julio de 2020 se dicta otra sentencia por parte del Tribunal Supremo (rec. 201/2018) en relación con la perspectiva de género en su dimensión vertical. En concreto, se trata de determinar si la incapacidad permanente derivada de complicaciones en el parto es un accidente no laboral o enfermedad común, habida cuenta de las diferencias más ventajosas en la acción protectora del primer supuesto respecto del segundo -principalmente, en lo que afecta al periodo de cotización previa y al cálculo de la base reguladora-. Parece, al menos a primera vista, que la metodología descrita no resulta tan sencilla de aplicar al presente caso, pues no se cuestiona el cumplimiento de requisitos normativos que pudieran encerrar una discriminación indirecta, sino que se pone en cuestión la conceptualización de dos instituciones jurídicas como son el accidente o enfermedad no laboral.

Con todo, el tribunal intenta su aplicación metodológica. En este sentido, más que partir de la definición legal de accidente no laboral y de enfermedad común, dada la vaguedad de la norma, el punto de partida lo marca el concepto jurisprudencial de accidente no laboral, definido por el propio TS como "acción súbita, violenta y externa". Aunque no lo diga la sentencia, el TS entiende que una aplicación automática y literal de su propia doctrina conllevaría a provocar un impacto de género discriminatorio en la sociedad, en la medida en que, dada la especificidad y singularidad del embarazo y parto, solamente afectaría negativamente a las mujeres exigir la concurrencia del requisito de "acción externa". En lugar de aplicar su propia metodología por la imposibilidad de encontrar un grupo de referencia respecto del cual predicar la discriminación, el TS trata de justificar conceptualmente que "lo ocurrido en un parto se asemeja más a la acción súbita y violenta inherente al concepto de accidente". Asimismo, introduce un matiz no menos relevante para realizar una interpretación por igualdad que deja atrás el elemento comparativo hasta ahora empleado y se centra exclusivamente en la condición de mujer, por cuanto solamente las mujeres pueden encontrarse en esta situación sin parangón con ninguna intervención quirúrgica u hospitalaria al ser la maternidad y el parto un proceso natural no patológico. Como tercer paso, a la hora de proceder a aplicar criterios interpretativos que conduzcan a superar la discriminación encerrada en la norma, en esta ocasión al tratarse de una elaboración doctrinal propia se limita a corregir la misma, al tiempo que invoca los art. 4 y 15 de la LOI y el conjunto de sentencias dictadas en torno a los mismos.

La última sentencia que de momento integra la hermenéutica de género es la STS de 14 de octubre de 2020 (rec. 2753/2018). El conflicto jurídico es si debe aplicarse la norma en su literalidad para el acceso a la pensión de viudedad cuando la pareja de hecho mujer incumple el requisito legal de convivencia. Para entender el alcance e intensidad de la perspectiva de género en el caso, resulta esencial compartir que la convivencia había cesado en el año 2000; que en el año 2001 se acordó el cese de convivencia y se aprobó el convenio regulador sin pensión compensatoria; que en el año 2003 la causa penal por violencia machista fue archivada; y doce años más tarde, cuando por un accidente de tráfico fallece su antigua pareja de hecho, solicita la pensión de viudedad.

A la hora de aplicar la metodología descrita, se parte de que para las mujeres casadas o divorciadas víctimas de malos tratos no está previsto el requisito legal de convivencia con el maltratador para acceder a la pensión de viudedad ex. art. 174.2 LGSS. En este sentido, como punto de partida, la aplicación literal de la norma conduciría a excluir a las víctimas mujeres constituidas en pareja de hecho (o expareja) de este régimen protector y condenarlas a vivir con su maltratador para acceder a una prestación pública. A pesar de no existir sentencia condenatoria, se entiende probada 
"la violencia conyugal" y, en consecuencia, mediante un criterio finalista y analógico se exime del cumplimiento del requisito de la convivencia también para las parejas o ex parejas de hecho que hayan sufrido violencia conyugal a la hora de acceder a la pensión de viudedad.

Es evidente que se seguirán dictando sentencias aplicando la perspectiva de género que pongan de manifiesto los vestigios sexistas que encierra nuestro ordenamiento jurídico. En este sentido, resultan reveladoras algunas sentencias de otros tribunales tratando asuntos que no han llegado al Tribunal Supremo de momento. Destacan las sentencias del TSJ de las Islas Canarias (Las Palmas) de 22 de junio de 2020 (rec. 310/2020) y 29 de enero de 2021 (rec. 940/2020), siendo la ponente de ambas la experta y activista en la materia Gloria Poyatos Matas. En la primera se interpreta el requisito de convivencia para acceder a las prestaciones en favor de familiares. Así, el tribunal entiende que debe estudiarse el conflicto desde una perspectiva de género en la medida en que dichas prestaciones son percibidas mayoritariamente por mujeres, en correspondencia con el trabajo de los cuidados, que también recae mayoritariamente sobre ellas según los datos que aporta del INSS. Así pues, una vez identificado el grupo socialmente afectado principalmente por la norma, constituido por mujeres, procede a interpretarse la misma no de forma literal, pues ello conllevaría un impacto de género en la sociedad discriminatorio, sino desde un punto de vista sistemático y finalista, de tal suerte que el requisito de convivencia engloba no solo la cohabitación, sino la efectividad de las atenciones y cuidados. Sorprende, por lo demás, que la decisión hubiera sido idéntica para el caso que el solicitante de la prestación fuera un hombre, pues el tribunal aplica la doctrina antigua del Tribunal Supremo en cuanto a la definición de convivencia para el acceso a este tipo de prestaciones (STS de 9 de febrero de 1985, rec. 355/1984). Por esta razón llama la atención de que la sentencia dedique gran parte de su razonamiento a explicar el origen, virtualidad, fundamento y fases de la perspectiva de género como hermenéutica judicial.

En la segunda de las sentencias referidas, la controversia pasa por interpretar el concepto de familia numerosa a efectos de determinar el umbral económico para acceder a las prestaciones no contributivas por hijo a cargo reguladas en el antiguo art. 352 LGSS (reformado en 2020). Al igual que en el caso anterior, la aplicación de la perspectiva de género no se realiza correctamente, pues la primera tarea debiera consistir en detectar la laguna o déficit normativo que, al encerrar un vestigio machista, pudiera traducirse, a la hora de aplicarla, en un impacto social que perpetuase el estereotipo machista contra la mujer. Tampoco se identifica el grupo social con el que contrastar y de cuya comparación se derivaría una potencial discriminación. En su lugar, el tribunal constata que se trata de una norma que afecta principalmente a las mujeres, por cuanto el grupo de beneficiarios de la prestación que regula está formado mayoritariamente por mujeres. Ello le empuja a tener una especial sensibilización hacia la mujer y, de nuevo, tras realizar un estudio cuasi doctrinal sobre la perspectiva de género, sorprende que el conflicto se resuelva gracias a una lectura sistemática y literal de las normas.

\subsection{La aplicación horizontal de la perspectiva de género}

La primera sentencia en la que el TS aplica la perspectiva de género en el plano horizontal, es decir, en un conflicto jurídico entre empresa y trabajadora, donde la pretensión ya no es, como en el plano vertical, el reconocimiento de una prestación social, sino el de un derecho laboral a cargo del empleador, es en la conocida STS de 13 de noviembre de 2019 (rec. 75/2018). Como se sabe, el conflicto jurídico entre las partes se cińe a si los trabajadores puestos a disposición por las ETT tienen derecho o no a que la empresa usuaria les aplique las medidas recogidas en su plan de igualdad. En esta ocasión, se intenta respetar y seguir la metodología aplicativa de la perspectiva de género fijada en la sentencia del año 2009. Así, se parte del cuestionamiento de la literalidad como único criterio hermenéutico para concluir que, sobre la base de este, sería posible dar ya una respuesta positiva a 
la cuestión dada la redacción del párrafo cuarto del art. 11 LETT. El siguiente paso, pese a poder dar por resuelto el conflicto, hubiera sido que el tribunal identificara al grupo social potencialmente discriminado compuesto por mujeres. Sin embargo, en el presente caso se omite dicha referencia al presentarse los planes de igualdad -cuya aplicación se reclama- como una protección en favor de las mujeres. Así, por último, se vuelve a emplear el criterio de no exclusión ("nada impide que se apliquen al trabajador puesto a disposición las medidas contenidas en ambos planes de manera complementaria") y el de la finalidad de la norma, en paralelo a la referencia a los art. 4 y 15 de la LOI, para concluir que debe evitarse realizar una interpretación sesgada y potenciar, por el contrario, una lectura favorecedora de la igualdad real en el ámbito de las relaciones en general. En fin, por vez primera y de forma expresa se aplica horizontalmente este criterio hermenéutico.

Siguiendo esta senda, un mes después el Pleno del TS confirma la aplicación de la perspectiva de género en un plano horizontal en la sentencia de 3 de diciembre de 2019 (rec. 141/2018). El conflicto jurídico radica en la validez de un acuerdo de modificación sustancial de condiciones de trabajo de carácter colectivo en el que se pacta un complemento salarial que no se devenga, en general, durante las ausencias del puesto de trabajo y, en concreto, durante los periodos de suspensión por maternidad o riesgo en el embarazo ni lactancia. El TS entiende que "tan amplio e indiscriminado alcance nos obliga a hacer una labor interpretativa del acuerdo para fijar los límites en los que pudiera colisionar con materias de derecho necesario". Metodológicamente la sentencia, al aplicar la perspectiva de género, parte de que la literalidad del acuerdo sí entra en colisión con el derecho a la igualdad efectiva por cuanto penaliza el ejercicio de la corresponsabilidad parental como instrumento de consecución de dicho principio ${ }^{14}$. Se presenta así el principio pro conciliación responsable como plasmación de la perspectiva de género en un plano horizontal. A continuación se acude al conocimiento general de la realidad sociológica para entender que, en tanto en cuanto los deberes parentales se asocian culturalmente a la figura de la mujer, el hecho de penalizar el disfrute de los derechos de conciliación, aunque se haga de forma neutral, afectará más a las mujeres en la medida que los hombres no accederán a estos instrumentos de corresponsabilidad familiar.

A partir de esta consideración, el tribunal va analizando cada tipo de suspensión legal posible y su alcance como instrumento activo de igualdad de mujeres y hombres en el marco de la corresponsabilidad familiar, para concluir que en aquellos casos en los que se de esa relación, el acuerdo de modificación sustancial es discriminatorio y, por lo tanto, nulo.

No obstante, en su análisis, se echa en falta que el tribunal haga referencia a algún informe o dato sociológico que sustente este razonamiento en cada una de las ausencias del puesto de trabajo analizadas. A diferencia de la metodología fijada en la sentencia del ańo 2009, se prescinde de la demostración empírica de los estereotipos discriminatorios de la sociedad para, en su lugar, darlos sencillamente como realidades conocidas y sin necesidad de prueba. No solo por razones básicas de argumentación jurídica en las que se hace depender el sentido del fallo, sino especialmente como mecanismo de denuncia y visibilidad de la discriminación social en la que se encuentran sus víctimas. En su lugar, se reitera en más de una ocasión que se trata de datos "manifiestamente notorios y conocidos en la realidad social que nos envuelve". Como excepción a esta metodología sin datos, el TS emplea como evidencia la Encuesta Nacional de Condiciones de Trabajo del año 2015, en conexión con el análisis que se hace del permiso del art. 37.3.b) ET (permiso de accidente u hos-

${ }^{14}$ En un sentido similar, STS de 23 de septiembre de 2020 (rec. 70/2019). Aunque no se refiere expresamente a la perspectiva de género como canon hermenéutico, señala que en nuestro ordenamiento jurídico la colaboración en el cuidado de los hijos comunes (art. 39.3 CE) incumbe a ambos progenitores (STC 128/1987, de 16 de julio), por lo que, tanto una regulación que fomente la dedicación exclusiva o prioritaria de la mujer a las tareas domésticas, como una regulación que desincentive el disfrute total o parcial del permiso de paternidad, es jurídicamente inadmisible por constituir una clara discriminación por razón de sexo. 
pitalización de familiares). Aun así, el TS reconoce que carece de estudios más específico sobre el número de trabajadoras en contraste con el de trabajadores que hacen uso de este permiso, pero entiende "que resulta suficiente para constatar" la diferencia sociológica en su disfrute.

Por último, respecto a esta sentencia, debe ponerse de manifiesto que la aplicación de la perspectiva de género en el plano horizontal, en el modo concreto en el que se realiza, no resulta pacífica entre los magistrados. Así, cuenta con un voto particular suscrito por dos magistrados en el que defienden razones de pura legalidad para entender que la remuneración debe mantenerse durante los permisos remunerados que la Ley contempla, con independencia de que se persiga la satisfacción de derechos o libertades constitucionales. Más interesante, si cabe, son las consideraciones que realizan en torno a la poca justificación a la hora de vincular cada permiso concreto con su potencial alcance como instrumento de corresponsabilidad. Así, se cuestiona que se califique como objetivamente neutro y se excluya de esa "consideración promocional" el permiso de traslado de domicilio, por ejemplo.

Como se ha dicho antes, es posible localizar pronunciamientos judiciales de otros tribunales y juzgados que aplican igualmente la perspectiva de género como canon hermenéutico, si bien los temas abordados y los conflictos jurídicos son los mismos que los expuestos en las sentencias del Tribunal Supremo. Con todo, sí es posible encontrarse con algún conflicto reciente que aún no ha llegado al alto tribunal. Así, la STSJ de Cantabria de 18 de enero de 2019 (rec. 833/2018) dilucida si el despido de una trabajadora en situación de Incapacidad Temporal por padecer cáncer de útero, sin que concurra causa objetiva o disciplinaria para ello, debe calificarse como procedente o nulo por ser discriminatorio. A este respecto, después de un extenso repaso por la jurisprudencia comunitaria y constitucional diferenciando los conceptos de discapacidad y enfermedad, el tribunal entiende que, al ser este tipo de cáncer una enfermedad de larga duración al no presentar perspectiva de recuperación delimitada a corto plazo, y que su tratamiento limita la participación plena y efectiva en la vida profesional, el despido debe calificarse como nulo. La importancia de la perspectiva de género es residual por cuanto aparece simplemente mencionada, si bien no la aplica ni la desarrolla, aunque introduce un matiz cuestionable de que al ser una "patología netamente femenina" debe enjuiciarse con perspectiva de género. Parece que la discriminación tiene su origen en la discapacidad y no en el sexo de la trabajadora, por lo que esta consideración final lejos de manifestar la relevancia de la perspectiva de género, la denosta al obviar los presupuestos aplicativos de la misma.

Otro caso de aplicación horizontal de la perspectiva de género es el resuelto en la STSJ de Madrid de 17 de diciembre de 2020 (rec. 388/2020). El conflicto jurídico consiste en dilucidar si el ejercicio del derecho a la reducción de la jornada por guarda legal del art. 37.6 ET integra, a su vez, el derecho a cambiar el turno al que se encuentra adscrita la trabajadora. El convenio aplicable, que podría establecer los criterios para la concreción horaria de dicha reducción, se limita a repetir lo previsto en el art. 37.7 ET al señalar que corresponderá al trabajador la concreción horaria dentro su jornada ordinaria. Pues bien, el tribunal trae a colación la perspectiva de género como elemento de ponderación de los derechos en juego, para concluir que existiendo una relación asimétrica entre mujeres y hombres, debe primar la tutela del derecho a la conciliación de la vida laboral y familiar, condenando a la empresa por discriminación por razón de sexo al no haber justificado suficientemente, según la opinión del tribunal, la denegación de la solicitud de la trabajadora. Está por verse si esta conceptualización de la perspectiva de género, no ya como canon hermenéutico de normas, sino como elemento de ponderación en favor de los derechos del trabajador en un conflicto con la empresa se mantiene y es asumido por parte del Tribunal Supremo en el futuro ${ }^{15}$.

${ }^{15}$ Debe advertirse que el TC en su sentencia 3/2007 de 15 de enero ya se había pronunciado en un caso similar, concediendo el amparo a la trabajadora basando su argumentación jurídica en la existencia de una discriminación indirecta, sin referencia a la perspectiva de género. 


\section{La frontera entre la función integradora y el activismo judicial. Una breve reflexión final}

Se ha dicho que la perspectiva de género no justifica la arbitrariedad ni fomenta la creatividad judicial al margen de la ley o contra legem, sino que se trata de materializar la función integradora del poder judicial mediante una sensibilidad que favorezca la igualdad entre sexos ejerciendo así una tutela antidiscriminatoria ${ }^{16}$. Sin embargo, algunas de las sentencias analizadas reflejan, por un lado, la frágil frontera entre la función legislativa y la función de integración del órgano judicial ${ }^{17} \mathrm{y}$, por otro lado, que la argumentación jurídica en la que se basa no siempre es constante y coherente, e incluso se convierte en un elemento de ponderación más que de interpretación normativa.

A este respecto, conviene no olvidar la regla general según la cual, la materialización del art. 9.2 de la CE corresponde, dada su complejidad, al legislador por cuanto sus decisiones gozan de una especial legitimidad, pues "un tribunal empeñado en integrar se convierte irremediablemente en legislador" ${ }^{18}$. Lejos de ser este un debate meramente teórico, la STS de 12 de febrero de 2021 (rec. 2839/2019) da muestra de la división interna en el Tribunal Supremo sobre cuáles deben ser los límites de la perspectiva de género y el alcance de la función integradora del poder judicial en esa función.

El sentir mayoritario de la Sala en esta sentencia rechaza integrar la perspectiva de género en su dimensión horizontal a pesar de que, como el recurso plantea, se dan los presupuestos que el propio TS ha fijado en su anterior doctrina: una norma aparentemente neutra pero que en su aplicación perjudica de modo mayoritario a las mujeres. Se trata de interpretar, nada más y nada menos, el art. 42 ET al no recoger como garantía la aplicación del convenio de la empresa principal permitiendo que las condiciones laborales de los trabajadores adscritos a la subcontrata sean inferiores. El TS reconoce que es notorio que, en el sector de la hostelería, el personal de pisos y limpieza está formado mayoritariamente por mujeres, pero que debe rechazarse una eventual discriminación indirecta por razón de género porque no se trata de un vestigio sexista ni un déficit o laguna normativa, sino que por el contrario "el silencio del legislador en esta materia opera con plena conciencia".

En contra, la magistrada Rosa María Virolés Piñol defiende en su voto particular reinterpretar el art. 42 ET con perspectiva de género con el objetivo de que se aplique el convenio que rige en la empresa principal, porque una lectura automática del precepto conduce al dumping social y a la precariedad de las condiciones laborales de las mujeres. A mayor abundamiento, y seguramente aquí está el auténtico debate, se argumenta que la función integradora opera no solo ante la ausencia de una norma aplicable al caso real, sino también cuando "la norma no considere la igualdad de sexos que debió haberse considerado".

Esta última reflexión es la que se esconde seguramente detrás de la interpretación y aplicación de las normas laborales desde una perspectiva de género, es decir, que el poder judicial tiene la doble obligación de identificar en la norma aplicable posibles discriminaciones indirectas derivadas de su aplicación y, a continuación, enmendar dicho impacto en sociedad corrigiendo al legislador mediante la función interpretativa.

Ahora bien, no debemos olvidar que la CE contempla un sistema de jurisdicción constitucional concentrado en el que los órganos judiciales deben actuar sometidos al imperio de la ley y a la

${ }^{16}$ ELÓSEGUI ITXASO, MARÍA, La igualdad de oportunidades. Modelos y referentes. Su influencia en el Derecho, en Vivas Larruy, A. (Dir.), La discriminación por razón de sexo tras 25 años en la Constitución española, Cuadernos de Derecho Judicial núm. 3, Madrid, CGPJ, 2004, pp. 414 y 415.

${ }^{17}$ RODRÍGUEZ GONZÁLEZ, SARAI, La perspectiva de género en la aplicación e interpretación de las normas por la Sala de lo Social del Tribunal Supremo, Trabajo y Derecho, núm. 76, 2021, p. 8.

${ }^{18}$ ALONSO GARCÍA, ENRIQUE, La interpretación de la Constitución. Madrid, Centro de Estudios constitucionales, 1984, p. 562. 
Constitución y, por tanto, si bien pueden cuestionar y examinar la constitucionalidad de las leyes, no por ello pueden dejar de aplicarlas, sino que deben, en todo caso, cuestionarlas ante el TC. Así, cuando por vía interpretativa no sea posible la acomodación de la norma al ordenamiento constitucional, procede el planteamiento de la cuestión de inconstitucionalidad ante el TC según lo previsto en el art. 5 de la LOPJ. Ejemplo de este correcto entendimiento de la depuración de las normas es la STC 103/1983, de 22 de noviembre, en la que a raíz de una cuestión de inconstitucionalidad, el TC entendió que el hecho de establecer un régimen legal más exigente para los viudos a la hora de acceder a la pensión de viudedad era contrario al principio de igualdad.

Otro ejemplo más reciente es la cuestión interna de inconstitucionalidad planteada por la Sala Segunda del Tribunal Constitucional que dio lugar a la Sentencia 91/2019 de 3 de julio en la que se resuelve, aplicando la metodología de perspectiva de género en sus tres pasos, que la norma que fija un porcentaje de parcialidad a la base reguladora de la pensión de jubilación es contraria al principio de igualdad efectiva porque esconde una discriminación indirecta por razón de sexo. Así, se localiza la norma aparentemente neutral y se cuestiona su constitucionalidad al provocar su aplicación un efecto discriminatorio contra la mujer. En segundo lugar, el TC delimita mediante cifras oficiales el grupo social perjudicado por la configuración legal de dicha regla en comparación respecto al grupo con el que se denuncia la diferenciación. Por último, el TC alcanza la conclusión, aplicando el principio de igualdad real, que dicha norma no debe tener cabida en nuestro ordenamiento jurídico y la declara nula.

No debe olvidarse, por tanto, que según el art. 163 de la CE y el 35.1 LOTC, cuando un órgano judicial considere, en algún proceso, que una norma con rango de ley, aplicable al caso, de cuya validez dependa el fallo, pueda ser contraria a la CE deberá plantear la cuestión ante el TC. La función integradora que implica la perspectiva de género encuentra un importante límite en este sentido, pues el juez no puede aplicar directamente la Constitución, obviando lo dispuesto en la ley, ya que ello supondría "la imposición del juez sobre la ley, lo que no está permitido por la Constitución"19. Ello no significa que los jueces no puedan, y de hecho, así deben hacerlo, realizar una interpretación de las leyes de acuerdo con la CE, pues entra dentro de la potestad jurisdiccional del art. 117.3 CE y lo hacen en virtud del principio de independencia judicial del art. 117.1 CE. Es más, a ello se suma la necesidad de preservar la validez de la ley gracias a su función interpretativa (SSTC 37/88 FJ 7 y 227/88 FJ 7), debiendo agotar las interpretaciones que la hagan conforme con la norma fundamental ${ }^{20}$. Así lo recoge el art. 5.1 de la LOPJ que apela a los jueces a interpretar las leyes conforme a los preceptos y principios constitucionales como paso previo a plantear la cuestión de inconstitucionalidad -si bien no se presenta como causa de admisión de dicha cuestión según la doctrina consolidada del propio TC, sino que ofrece una alternativa entre llevar a cabo la interpretación al caso concreto conforme la CE o plantear la cuestión de inconstitucionalidad (SSTC 105/88, 222/92 o 174/98).

Ahora bien, dicha libertad de interpretación de la norma conforme a la constitución encuentra dos límites importantes. Por un lado, tal y como señala el propio TC, el juez no puede desvirtuar el sentido de la ley para no plantear la cuestión, pues "la posibilidad de interpretar las normas tiene también sus límites y no puede llegar a entender que la norma dice lo contrario o algo sustancialmente distinto de lo que dice" (SSTC 34/81, 22/85 o 222/92). Por otro lado, la posibilidad de dictar sentencias interpretativas de las normas, dotándoles de un significado sustancialmente distinto al que derivaría de su literalidad para así, y solo así, mantener su vigencia conforme al texto

${ }^{19}$ FERNÁNDEZ DE FRUTOS, MARTA, El procedimiento de la cuestión de inconstitucionalidad, Madrid: Cedecs, 2005, p. 134.

${ }^{20}$ RUIZ MIGUEL, ALFONSO, La igualdad en la jurisprudencia del Tribunal Constitucional, en L. García San Miguel (Ed.), El principio de igualdad, Madrid: Dykinson, 2000, p. 165. 
constitucional es competencia exclusiva del Tribunal Constitucional. Una cosa es interpretar una norma en un caso determinado según los valores constitucionales y atendiendo, en particular, a la igualdad efectiva que deriva de los art. 14 y 9.2 CE; y otra cosa cualitativamente distinta es que el poder judicial participe de la conformación de la norma en cada caso y que el TS sustituya la labor del TC mediante la fijación de jurisprudencia aprovechándose de lo previsto en el art. 1.6 del CC. Así, corresponde solamente al TC, como intérprete supremo de la Constitución, no solo la fijación de la interpretación de las normas constitucionales, sino también la interpretación constitucional de las leyes que resulta vinculante para el resto de los poderes públicos, y en especial para los órganos judiciales en cuanto aplicadores del derecho ${ }^{21}$.

Estas consideraciones en torno a la posibilidad de dictar sentencias interpretativas por parte de la judicatura cobra máxima relevancia si se tiene en cuenta que la perspectiva de género como canon hermenéutico normalmente surge ante lagunas u olvidos de la norma. En los supuestos de posible vulneración del principio de igualdad por omisión o silencio legislativo, corresponde al Tribunal Constitucional hacer compatible dicha norma con el texto constitucional, por cuanto la omisión puede en ocasiones ser tanto como una contradicción, no pudiéndose calificar de inocua, indiferente o neutra. En estos casos, la interpretación conforme a la Constitución se vuelve más compleja, en la medida en la que no se trata de controlar la inactividad del legislador, sino las consecuencias jurídicas de dicha inactividad.

Es más, el propio TC es consciente de la dificultad para resolver la vulneración del principio de igualdad por omisiones legislativas relativas, pues "no se trata de suprimir o cancelar alguna de las partes de los preceptos, sino al contrario, de ampliar su objeto para incluir a aquellos que han sido excluidos sin justificación ninguna. En estos casos de omisión del legislador contraria a la Constitución, es el legislador, dentro de la libertad de configuración de que goza, derivada de su posición constitucional y, en última instancia, de su específica legitimidad democrática quien determine a la mayor brevedad el régimen legal con respecto al derecho de igualdad que ahora resulta vulnerado" (STC 52/2006 de 16 de febrero, FJ 3).

A pesar de esta rotundidad, lo cierto es que la sanción a una omisión legislativa relacionada con el principio de igualdad no pasa únicamente por realizar recomendaciones al legislador, sino que llega hasta las sentencias aditivas por parte del TC, cuya finalidad es la transformación del significado de la ley bajo control, más que su eliminación o su interpretación conforme ${ }^{22}$. Ejemplos de esta función positiva o integradora del TC podrían encontrarse en las SSTC 103/83 de 22 de noviembre y 14/83 de 23 de noviembre que extienden el derecho a una pensión de viudedad a los varones. De este modo, en los supuestos de violación de igualdad mediante omisión, el TC podría solucionar la inconstitucionalidad de la norma interpretando extensivamente la norma, incluyendo los supuestos omitidos o recurriendo a la analogía en virtud del principio «ubi est eadem ratio vel aequitas, idem ius statui debet».

A este respecto, no debe olvidarse que la inactividad del legislador puede constituir la expresión de una opción política y que corresponde al control de constitucionalidad expulsar los actos y omisiones que son contrarias a las previsiones constitucionales ${ }^{23}$. Así, en los supuestos de omisiones relativas, no puede ser el juez ordinario quien establezca su encaje en la Constitución, sino que mediante el remedio a la cuestión de inconstitucionalidad el TC podrá salvar, de forma limitada, dicha

${ }^{21}$ En profundidad, FERNÁNDEZ DE FRUTOS, MARTA, El procedimiento de la cuestión de inconstitucionalidad, Madrid: Cedecs, 2005, p. 190.

${ }^{22}$ AHUMADA RUIZ, Ma ÁNGELES, El control de constitucionalidad de las omisiones legislativas, Revista del Centro de Estudios Constitucionales, núm. 8, 1991, p. 184.

${ }^{23}$ VILLAVERDE MENÉNDEZ, IGNACIO, Los remedios de inconstitucionalidad por omisión, Justicia Electoral, núm. 16, 2015, p. 216. 
omisión dictando una sentencia aditiva gracias a una lectura extensiva y analógica de la norma que colme su vacío relativo ${ }^{24}$.

En consecuencia, sobre el principio de división de poderes y la naturaleza del Tribunal Constitucional se conjuga la imposibilidad de que el poder judicial supla las omisiones legislativas relativas dictando sentencias "adjuntivas y reorientadoras" de la literalidad de la norma que permitan reparar la infracción constitucional y que, en su caso, vinculen al resto de tribunales y juzgados. La tarea de la función legisladora como consecuencia del control de los valores y principios constitucionales le corresponde de forma limitada, autocontenida y en exclusiva al Tribunal Constitucional ${ }^{25}$.

En fin, la perspectiva de género como canon hermenéutico conecta con un debate tradicional entre los constitucionalistas en torno dónde acaba la interpretación conforme a la Constitución y dónde empieza el activismo judicial. Por ello, convendría no perder de vista el principio de autocontención, del imperio de la ley y de seguridad jurídica que limitan la función interpretativa de la jurisdicción ordinaria, pues como se ha denunciado ${ }^{26}$, en caso contrario, se corre el riesgo de que el poder judicial acabe participando en la conformación de la norma. No se niega la independencia de los jueces para aplicar e interpretar las normas para acomodarlas a los principios y valores constitucionales. La reflexión que trato de compartir es que en los supuestos de omisiones legislativas relativas y contrarias al principio de igualdad, en la medida que exigen de una sentencia aditiva como solución, debe ser el Tribunal Constitucional quien asuma esta función, como máximo intérprete de la constitución, de forma limitada y extraordinaria, de legislador en positivo. Así, y por lo que respecta al poder judicial, en el momento en el que la interpretación conforme implicara dictar una sentencia adjuntiva, debería presentar la procedente cuestión de inconstitucionalidad, pues con ello se alcanzaría una mayor seguridad jurídica y, por consiguiente, una mayor protección para la igualdad efectiva entre mujeres y hombres.

\section{Bibliografía}

AHUMADA RUIZ, Ma ÁNGELES, El control de constitucionalidad de las omisiones legislativas, Revista del Centro de Estudios Constitucionales, núm. 8, 1991, pp. 169-194.

ALONSO GARCÍA, ENRIQUE, La interpretación de la Constitución. Madrid, Centro de Estudios constitucionales, 1984

ELÓSEGUI ITXASO, MARÍA, La igualdad de oportunidades. Modelos y referentes. Su influencia en el Derecho, en Vivas Larruy, A. (Dir.), La discriminación por razón de sexo tras 25 años en la Constitución española, Cuadernos de Derecho Judicial núm. 3, CGPJ, Madrid, 2004, pp. 411-448.

FERNÁNDEZ DE FRUTOS, MARTA, El procedimiento de la cuestión de inconstitucionalidad, Madrid: Cedecs, 2005.

GIL RUIZ, JUANA MARÍA, La interpretación de las normas bajo una perspectiva de género, 2013, Disponible en: (20/04/2021) https://www.poderjudicial.es/stfls/CGPJ/OBSERVATORIO\%20DE \%20VIOLENCIA\%20DOM\%C3\%89STICA/OTRAS\%20ACTIVIDADES\%20FORMATIVAS/FICHEROS/20130502\%20JP\%20La\%20interpretaci\%C3\%B3n\%20de\%20 las\%20normas\%20bajo....pdf

${ }^{24}$ Ibidem, p. 232.

${ }^{25}$ REQUEJO PAGÉS, JUAN LUIS, Los problemas de la omisión legislativa en la jurisprudencia constitucional, XIC Conferencia de Tribunales Constitucionales Europeos, 2008, pp. 6, 34 y 43 (consultado 23/04/21). Disponible en ver bibliografía.

${ }^{26}$ GOERLICH PESET, JOSÉ MARÍA, La aplicación de las normas internacionales del trabajo por los tribunales españoles, Labos, vol. 2, núm. 1, 2021, p. 13. 
GOERLICH PESET, JOSÉ MARÍA, La aplicación de las normas internacionales del trabajo por los tribunales españoles, Labos, vol. 2, núm. 1, 2021, pp. 4-17.

JIMÉNEZ HIDALGO, ADORACIÓN, La precariedad laboral: desigualdad y discriminación, 2018, http://www.mujeresjuezas.es/2019/01/14/juzgar-con-perspectiva-de-genero-en-la-jurisidiccion-de-lo-social-novedoso-e-interesante-articulo-de-nuestra-socia-adoracion-jimenezhidalgo/ (21/04/2021).

LOUSADA AROCHENA, JOSÉ FERNANDO, La integración de la perspectiva de género en la aplicación e interpretación de las normas por la jurisdicción social, Revista de Derecho Social, núm. 91, 2020, pp. 39-58.

MERCADER UGUINA, JESÚS R., Los principios de aplicación del Derecho del Trabajo. Formación, decadencia y crisis, Valencia: Tirant lo Blanch, 2014.

MOLINA NAVARRETE, CRISTÓBAL, Una cuestión de género en la justicia social: asignatura aún pendiente, también del Tribunal Supremo, Revista de Trabajo y Seguridad Social CEF, núm. 453, 2020, pp. 5-30.

MONTOYA MELGAR, ALFREDO, La aplicación del Derecho del Trabajo y el sistema de principios, valores y derechos fundamentales, Revista del Ministerio de Trabajo e Inmigración, núm. 88, 2011, pp. 13-29.

POYATOS I MATAS, GLÒRIA, Juzgar con perspectiva de género: una metodología vinculante de justicia equitativa, IQUAL. Revista de Género e Igualdad, núm. 2, 2019, pp. 1-21.

RODRÍGUEZ-PINEERO Y BRAVO-FERRER, MIGUEL, Principio de igualdad y Derecho del Trabajo, en XI Jornadas de Estudio El principio de Igualdad en la Constitución española, vol. 2, Madrid, Ministerio de Justicia, 1991, pp. 1069-1100.

RAMOS QUINTANA, MARGARITA ISABEL, Lesiones en el parto y seguridad social: el enquistamiento de las discriminaciones de sexo y de género, Trabajo y Derecho Nueva Revista de actualidad y relaciones laborales, núm. 71, 2020, pp. 1-6.

REQUEJO PAGÉS, JUAN LUIS, Los problemas de la omisión legislativa en la jurisprudencia constitucional, XIC Conferencia de Tribunales Constitucionales Europeos, 2008 (consultado 23/04/21). https://www.tribunalconstitucional.es/es/publicaciones/Publicaciones/Coedicion-TCEuropeos-II.pdf

RODRÍGUEZ GONZÁLEZ, SARAI, La perspectiva de género en la aplicación e interpretación de las normas por la Sala de lo Social del Tribunal Supremo, Trabajo y Derecho, núm. 76, 2021, pp. 1-14.

RUIZ MIGUEL, ALFONSO, La igualdad en la jurisprudencia del Tribunal Constitucional, en L. García San Miguel (Ed.), El principio de igualdad, Madrid: Dykinson, 2000, pp. 155-200.

VILLAVERDE MENÉNDEZ, IGNACIO, Los remedios de inconstitucionalidad por omisión, Justicia Electoral, núm. 16, 2015, pp. 195-271. 